\title{
Heavy iron in sublithospheric diamonds reveals deep serpentinite subduction
}

\author{
EVAN SMITH ${ }^{1}$, PENG NI ${ }^{2}$, STEVEN B. SHIREY ${ }^{3}$, \\ STEPHEN H. RICHARDSON ${ }^{4}$, WUYI WANG ${ }^{1}$ AND ANAT \\ SHAHAR $^{2}$ \\ ${ }^{1}$ Gemological Institute of America \\ ${ }^{2}$ Earth and Planets Laboratory, Carnegie Institution for Science \\ ${ }^{3}$ Carnegie Institution for Science \\ ${ }^{4}$ University of Cape Town \\ Presenting Author: smithevanm@gmail.com
}

Serpentinite subduction represents a key pathway for the deep recycling of water and other surficial components. Whereas sediments and ocean crust are largely devolatilized in fore- and sub-arc regions, serpentinized peridotite in the cooler, interior mantle portion of slabs may survive to greater depths. Such serpentinite subduction has been proposed to account for deep focus earthquakes [1] as well as certain geochemical features arising in mantle-derived basalts at ocean islands and mid-ocean ridges.

We have discovered a remarkably heavy iron isotopic composition in inclusions from large, gemmy, sublithospheric diamonds that serves as deeply-sourced evidence of subducted serpentinite [2]. These so-called CLIPPIR diamonds from Letseng, Lesotho, originate from depths within $360-750 \mathrm{~km}$. The three metallic $\mathrm{Fe}-\mathrm{Ni}-\mathrm{C}-\mathrm{S}$ inclusions analyzed possess heavy iron signatures, $\delta^{56} \mathrm{Fe}=0.79-0.90 \%$, that lie far outside the near $0 \%$ range of known mantle compositions or expected reaction products at depth. Instead, this signature can be accounted for by subducted iron sourced from magnetite and/or $\mathrm{Fe}-\mathrm{Ni}$ alloys crystallized during seafloor serpentinization of oceanic peridotite. Unradiogenic osmium isotopic analyses $\left({ }^{187} \mathrm{Os} /{ }^{188} \mathrm{Os}=\right.$ 0.111 ) were obtained on two additional inclusions, which support the connection to subducted peridotite. Low-Os isotopic compositions produced by prior mantle convection and melt depletion are typical of abyssal peridotites.

These metallic inclusions provide physical evidence that traces serpentinite subduction into the mantle transition zone. This not only demonstrates a key geochemical pathway for recycling, but also unveils a striking recycling-related iron isotopic signature in the deep mantle. This isotopically heavy metallic iron from subducted serpentinized oceanic lithosphere could lead to a subtle but systematic recycling-related heterogeneity in the convecting mantle and help to account for the multifarious iron isotope systematics in oceanic basalts.

[1] Shirey, Wagner, Walter, Pearson \& van Keken (2021), Slab transport of fluids to deep focus earthquake depths Thermal modeling constraints and evidence from diamonds. AGU Advances, in press. DOI: 10.1029/2020AV000304.

[2] Smith, Ni, Shirey, Richardson, Wang \& Shahar (2021), Heavy iron in large gem diamonds traces deep subduction of serpentinized ocean floor. Science Advances, in press. DOI: 10.1126/sciadv.abe9773. 